\title{
INTER-RELATIONS BETWEEN THE ARCTIC SEA ICE AND THE GENERAL CIRCULATION OF THE ATMOSPHERE*
}

\author{
By G. WENDLER and Y. NAGASHIMA
}

(Geophysical Institute, University of Alaska-Fairbanks, Fairbanks, Alaska 99775-0800, U.S.A.)

\begin{abstract}
Satellite imagery has substantially improved the quality of sea-ice observation over the last decades. Therefore, for a 25 year period, a statistical study based on the monthly Arctic sea-ice data and the monthly mean 700 mbar maps of the Northern Hemisphere was carried out to establish the relationships between sea-ice conditions and the general circulation of the atmosphere. It was found that sea-ice conditions have two opposing effects on the zonal circulation intensity, depending on the season. Heavier than normal ice in winter causes stronger than normal zonal circulation in the subsequent months, whereas heavier than normal ice in the summer-fall causes weaker zonal circulation in the subsequent months. Analyzing the two sectors, the Atlantic and Pacific ones separately, a negative correlation was found, which means a heavy ice year in the Atlantic Ocean is normally associated with a light one in the Pacific Ocean and vice versa.
\end{abstract}

\section{INTRODUCTION}

The Arctic Ocean and the adjacent seas are covered by sea ice. The extent of the sea ice fluctuates seasonally; the maximum ice extent is formed in late February (approximately $14 \times 10^{6} \mathrm{~km}^{2}$ ), and the minimum ice extent is formed in late August (approximately $7 \times 10^{6} \mathrm{~km}^{2}$ ) (Walsh and Johnson, 1979[a]). As the sea ice consists of a great many individual ice fields, it is constantly moving under the action of the atmosphere and ocean currents, which leads to the fluctuation of the ice boundaries. Therefore, in addition to the seasonal fluctuation, sea ice also frequently undergoes large variations in extent from one year to another.

In studying the interaction between the sea ice and the atmosphere, we have to consider two effects, which work in opposite directions: (1) the effect of the sea ice on the atmosphere, and (2) the effect of the atmosphere on the sea ice. Together they form a complicated feed-back mechanism, as the effect of the atmosphere changes the extent of the sea ice, which in turn affects the atmosphere.

The polar regions act as heat sinks in the global circulation. Sea ice plays an important role here, because sea ice changes the surface heat budget in two ways: (1) the surface albedo is very high (about $80 \%$ for dry snow) compared to that of open water (about 10\%); (2) sea ice restricts the heat exchange between the atmosphere and the ocean. Therefore, the presence or absence of an ice cover over a large area of the ocean might substantially affect the heat budget of the polar atmosphere, and hence the general circulation.

One approach to large-scale ice-atmosphere interactions is to conduct a statistical study based on observations. Walsh and Johnson (1979[b]) conducted an eigenvector analysis to evaluate correlations between the dominant modes of sea-ice and atmospheric variability on monthly and seasonal timescales. Johnson (1980) examined simultaneous atmospheric fields during winter-time extreme ice conditions. However, there has been no systematic study of the relationships between sea-ice conditions and parameters of the general

*See Annals of Glaciology, Vol. 9, 1987, p. 252 for an extended abstract. circulation of the atmosphere, such as zonal index. Regarding the effect of sea ice on the zonal circulation intensity, one hypothesis goes as follows: a large extent of sea ice, due to the high albedo of its surface, decreases the amount of solar radiation absorbed as the surface increases regional heat loss, cools the atmosphere, intensifies the meridional temperature gradient and pressure gradient, and hence intensifies the zonal circulation.

The foregoing hypothesis seems to be true for the annual cycle. Indeed, Fletcher $(1965,1969)$ and van Loon (1979) showed a high correlation between the atmospheric heat loss and the zonal circulation intensity in the annual cycle.

In this paper, it is hoped to reveal the relationships between inter-annual variability of the sea ice and that of the general circulation parameters, such as zonal index. Our questions are: (1) how the anomalous ice conditions in a certain month of the year affect the zonal circulation intensity of the subsequent months; and conversely, (2) how the anomalous ice conditions in a certain month of the year affect the ice conditions of the subsequent months. A study based on the monthly Arctic sea-ice data and the monthly mean 700 mbar maps of the Northern Hemisphere was carried out to answer these questions. First, the manner of the sea-ice fluctuation is examined and, secondly, the relationships between the sea-ice fluctuation and the general circulation of the atmosphere are examined.

\section{DATA}

The available Arctic sea-ice data from various sources for 25 years (1953-77) were compiled by Walsh and Johnson (1979[a]) on a monthly basis and stored on tape; the complete data set was used for this study. The data sources are from aircraft, ship plus land observations, and most importantly from satellite. The series is not homogeneous in quality, with better data being available in the later years, with a larger amount and better quality of remotely sensed data. The concentration grids depict ice conditions at the end of each of 300 months (1953-77).

The monthly mean 700 mbar maps were chosen as sources of monthly meteorological data. Those weather maps were collected from the "Weather and circulation series" in the Monthly Weather Review (American Meteorological Society). The weather maps of 300 months together with the sea-ice data form the basis of this study.

\section{SEA-ICE FLUCTUATION}

Lines which connect $5 / 10$ concentration grid points in the print-out of the sea-ice data were taken as the ice limit. Since the ice limit is not confined by the continent in the Bering Sea area and the Greenland-Barents Seas area, the ice index is defined for these two regions, i.e. the ice index in the Pacific sector (IP) and the ice index in the Atlantic sector (IA). Each forms a time series composed of 300 monthly data points.

IP: Ice index in the Pacific sector: ice-limit position at the end of each month in the Bering Sea area, expressed in latitude (zonally averaged between long. $160^{\circ} \mathrm{W}$. and $170^{\circ} \mathrm{E}$.). 
IA: Ice index in the Atlantic sector: ice-limit position at the end of each month in the Greenland-Barents Seas, expressed in latitude (zonally averaged between long. $40^{\circ} \mathrm{E}$. and $\left.10^{\circ} \mathrm{W}.\right)$.

From the original series, deviation series were constructed by subtracting long-term mean values, i.e.

$$
\begin{aligned}
& X^{\prime}{ }_{i, m}=X_{i, m} 1 / 25^{*} \operatorname{SUM}\left(X_{i, m}\right) \text { for } i=1,25 \text { and } m= \\
& 1,1^{2} \text { where } X^{\prime}{ }_{i, m} \text { : component of the deviation series, } \\
& X_{i, m} \text { component of the original series, } 1 / 25^{*} \mathrm{SUM} \\
& \left(X_{i, m}\right): 25 \text { year mean for the } m \text { th month. }
\end{aligned}
$$

Subtracting the long-term mean values removes the seasonal cycle. The fluctuation of the ice-field limit was analyzed using the time series IP and IA, and also their anomaly series IP' and IA'. (The notations with and without primes denote anomaly and original series, respectively.)

Figure 1 shows the annual cycle of the ice-limit position. These are the plots of 25 year mean values for

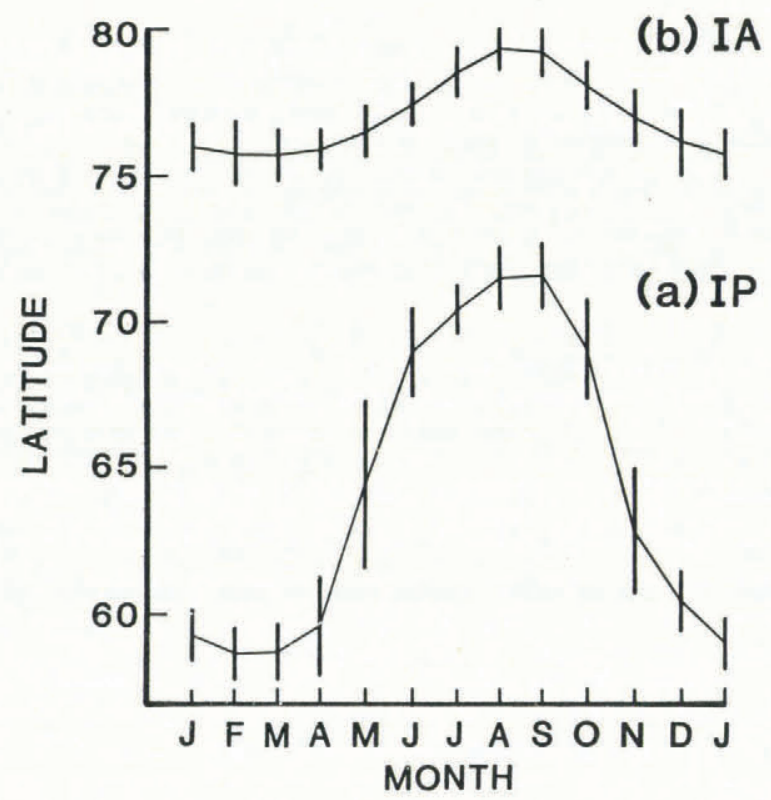

Fig. 1. Annual cycle of the ice-limit position: (a) Pacific sector (IP). (b) Atlantic sector (IA). Vertical bars denote standard deviation.

each month derived from the original series. It is apparent that the latitudes are different between the two indices. The ice limit in the Atlantic sector is over $10^{\circ}$ more northerly than in the Pacific sector. The Gulf Stream in the Atlantic Ocean works much more effectively than its counterpart in the Pacific. For both regions, the ice limit is commonly at the southernmost location (maximum ice extent) in February and March, and the northernmost location (minimum ice extent) in August and September. But the annual ranges are different: the annual range of IP (about $13^{\circ}$ ) is larger than that of IA (about $4^{\circ}$ ). The error bars in the graphs depict one standard deviation of 25 values. It is noteworthy that in IP the standard deviation is large during the transitional season but relatively small during the months with maximum and minimum ice extent. The small inter-annual variability of the winter-time ice-limit position is probably due to a dynamic control of shelf-edge currents as suggested by Muench and Ahlnas (1976). They pointed out that the latent heat needed for melting ice is in semi-equilibrium with the advection of warm $\left(2-4^{\circ} \mathrm{C}\right)$ water in this region. The standard deviations for IA are almost the same throughout the year and are relatively small $\left(1^{\circ}\right)$. The small annual and inter-annual variability in the ice-limit position in the Atlantic sector is probably due to the stabilizing effect of the warm ocean currents in the North Atlantic, the same mechanism as discussed in the Pacific sector.

The extent of persistence and possible periodicity can be examined by calculating the autocorrelations. The autocorrelations of the original series show a distinct 12 month periodicity reflecting the annual cycle, whereas such a periodicity is not seen in the anomaly series. However, the comparison of the autocorrelations of IP' $^{\prime}$ to those of ' $\mathrm{IA}^{\prime}$ shows that the persistence of anomalies is indeed larger in IA $^{\prime}$ than IP'.

According to Walsh and Johnson (1979[a]), the frequency spectrum of the anomaly series of the sea-ice extent over the entire polar cap showed a significant spectral peak at 12 months. This was attributed to the fact that the summer variance exceeds the winter variance due to the lack of inter-annual winter variability along the northern coastlines of Northern America and Asia. However, as the ice index in this study is based on the region where there is no constraint of the continents, even such a periodicity as 12 months is not distinct.

It is of interest to examine the relationship of IP $^{\prime}$ and $\mathrm{IA}^{\prime}$, and this can be done by calculating the crosscorrelations. Figure 2 shows the cross-correlations between

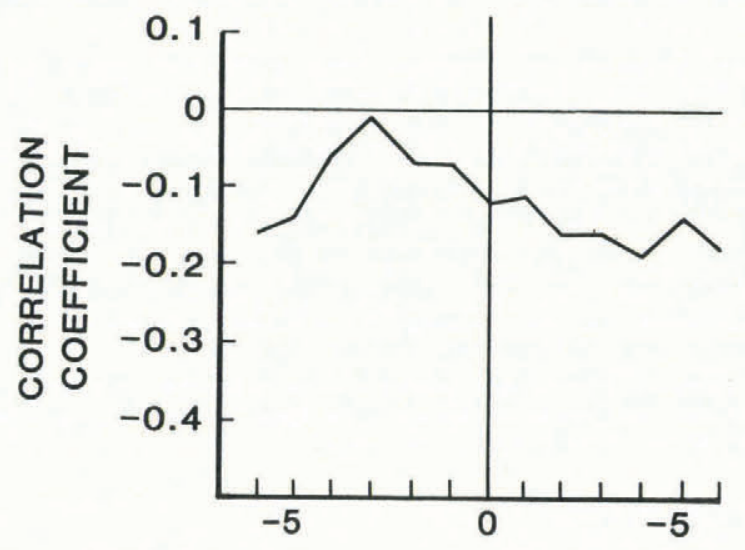

LAG TIME IN MONTH OF IA'

Fig. 2. Cross-correlations between the anomaly series of the ice index in the Pacific sector (IP') and the anomaly series of the ice index in the Atlantic sector $\left(I A^{\prime}\right)$.

IP' and IA'. The negative sign of the zero-lag crosscorrelation indicates that the simultaneous anomalies tend to be out of phase between the two locations. This is in good agreement with the result of the study by Walsh and Johnson (1979[a]), in which the first eigenvector of the anomaly field describes fluctuations characterized by an outof-phase relationship between the North Atlantic area and the remainder of the polar cap.

The results of the analysis are summarized in Table I. Since the fluctuations of the ice-limit positions in the Pacific sector and the Atlantic sector have some different features, and the simultaneous anomalies are not positively correlated, the Northern Hemisphere is divided into two sectors (the Pacific sector and the Atlantic sector) at long.

TABLE I. SUMMARY OF THE SEA-ICE FLUCTUATIONS
General location

Annual range variability

Persistence

Periodicity (original series)

Periodicity (anomaly series)

Simultaneous relationship between anomaly series
Inter-annual
Pacific sector (IP, IP')

Atlantic sector (IA, IA ${ }^{\prime}$ )

$59^{\circ} \mathrm{N} .-72^{\circ} \mathrm{N} . \quad 76^{\circ} \mathrm{N} .-80^{\circ} \mathrm{N}$.

Large $\left(13^{\circ}\right)$

Small $\left(4^{\circ}\right)$

\section{Large \\ Small}

Small

Large

12 months

12 months
None 
$90^{\circ} \mathrm{E}$. and $90^{\circ} \mathrm{W}$., and the relationships between sea-ice conditions and the general circulation of the atmosphere are examined for each sector.

RELATIONSHIP BETWEEN SEA-ICE CONDITIONS AND GENERAL CIRCULATION OF THE ATMOSPHERE

The zonal index is a measure of the intensity of westerly winds. Here, it is defined as the geopotential height difference between lat. $40^{\circ} \mathrm{N}$. and $60^{\circ} \mathrm{N}$. on the monthly mean 700 mbar maps, zonally averaged in each sector. The grid spacing was $10^{\circ}$ of longitude, and the zonally averaged values were derived.

ZP: Zonal index in the Pacific sector: geopotential height difference between lat. $40^{\circ} \mathrm{N}$. and $60^{\circ} \mathrm{N}$. on the monthly mean 700 mbar map, zonally averaged in the sector (long. $90^{\circ} \mathrm{W}$. - westward - $90^{\circ} \mathrm{E}$.).

ZA: Zonal index in the Atlantic sector: geopotential height difference between lat. $40^{\circ} \mathrm{N}$. and $60^{\circ} \mathrm{N}$. on the monthly mean $700 \mathrm{mbar}$ map, zonally averaged in the sector (long. $90^{\circ} \mathrm{W}$. - eastward $-90^{\circ} \mathrm{E}$.).

Time series of 300 data points were constructed. As stated above, our hypothesis is that heavy ice conditions intensify the zonal circulation. In order to verify this hypothesis, the calculations of cross-correlations between the ice index and the zonal index based on the sequence of 300 data points was attempted but the result was not significant. Therefore, it was assumed that there might be a seasonal dependence in the effect; and the anomalies of the ice index were compared to the anomalies of the zonal index from month to month. In order to examine the effect of the sea ice on the zonal circulation, correlation coefficients between the ice index for each month and the zonal index of the contemporary and subsequent months (up to 5 months) were calculated.

The correlation analysis, based on the zonal index for the entire circle $\left(360^{\circ}\right)$, was also attempted but the result was not significant. Therefore, it seems reasonable to divide the Northern Hemisphere into two sectors and see how the ice conditions in each sector affect the general circulation in the same sector.

Tables II and III show the results of the correlation analysis. Table II shows the correlation between the ice index in the Pacific sector (IP') and the zonal index in the Pacific sector $\left(Z^{\prime}\right)$. Table III shows the correlation between the ice index in the Atlantic sector $\left(\mathrm{IA}^{\prime}\right)$ and the zonal index in the Atlantic sector $\left(\mathrm{ZA}^{\prime}\right)$. The calculation of the correlation coefficients is based on 25 pairs of data points (except those in the lower left, for which 24 pairs of data points were used), and application of the $t$-test shows that coefficients with an absolute value of 0.4 or more are significant at a $95 \%$ confidence level. As we have a large number of correlation coefficients, some "good" correlations might occur by chance only. Hence, we considered only clusters of correlation factors.

Table II shows negative correlations between the winter-spring ice indices and the zonal indices of the following months (April-June). For example, the correlation coefficient is -0.47 for February ice versus the June zonal index. The opposite relationship is seen in the November zonal index. The correlation coefficients between the November zonal index and the ice indices for the preceding months are all positive. For example, the correlation coefficient is 0.54 for September ice versus the November zonal index.

\section{TABLE III. CORRELATION COEFFICIENTS BETWEEN ICE INDEX (IA') AND ZONAL INDEX} $\left(\mathrm{ZA}^{\prime}\right)$ - ATLANTIC SECTOR

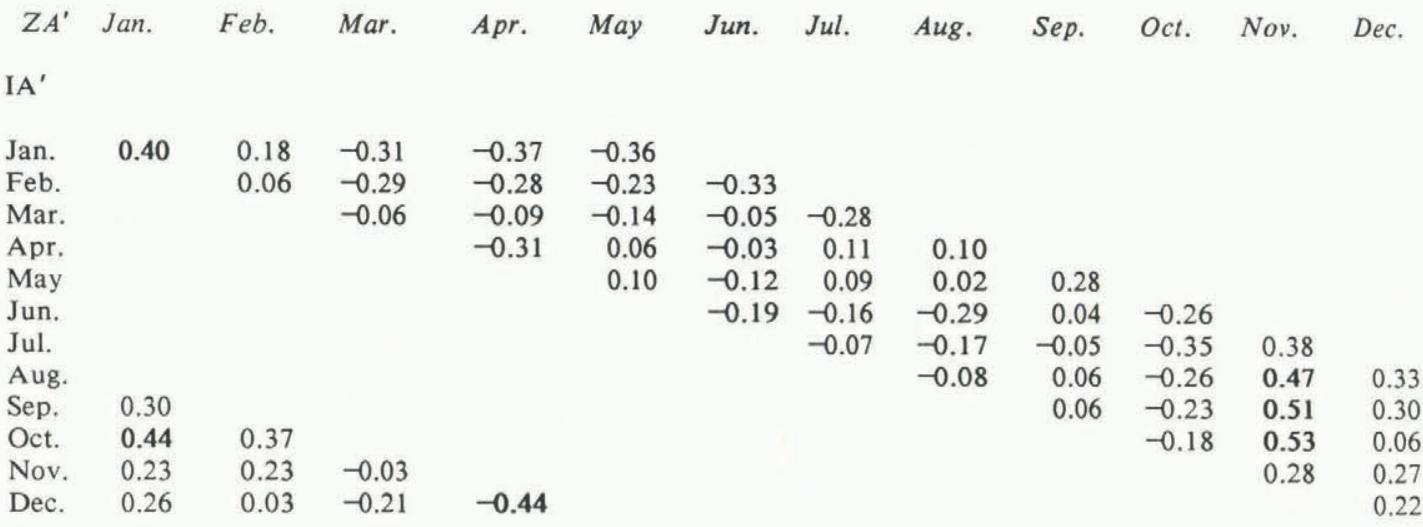

TABLE II. CORRELATION COEFFICIENTS BETWEEN ICE INDEX (IP') AND ZONAL INDEX $\left(\mathrm{ZP}^{\prime}\right)$ - PACIFIC SECTOR

ZP' Jan. Feb. Mar. Apr. May Jun. Jul. Aug. Sep. Oct. Nov. Dec.

IP'

$\begin{array}{lrrr}\text { Jan. } & -0.11 & -0.30 & 0.02 \\ \text { Feb. } & & 0.01 & 0.05 \\ \text { Mar. } & & & -0.25 \\ \text { Apr. } & & & \\ \text { May } & & & \\ \text { Jun. } & & & \\ \text { Jul. } & & & \\ \text { Aug. } & & & \\ \text { Sep. } & 0.09 & & \\ \text { Oct. } & -0.34 & -0.37 & \\ \text { Nov. } & 0.18 & 0.39 & -0.11 \\ \text { Dec. } & 0.14 & -0.14 & -0.01\end{array}$

$0.34-0.22$

$-0.25 \quad-0.22$

$-0.10 \quad-0.11$

$\begin{array}{ll}0.06 & -0.09 \\ & -0.47\end{array}$
-0.47
-0.11
-0.02
-0.36

$-0.21$
-0.03
-0.10
-0.32
-0.36
-0.32
0.23

$-0.13-0.30$

$\begin{array}{rl}-0.06 & 0.08\end{array}$

$-0.02 \quad 0.00$

$-0.04$

$-0.12$

$-0.31$
0.17

$0.22-0.13$

$0.54-0.03$

$0.23-0.10$

$0.24 \quad 0.26$
33
.30

0.06

0.22

$\begin{array}{llll}\text { Dec. } \quad 0.14 & -0.14 & -0.01 & 0.24\end{array}$


These features are more distinct in Table III. Again, the negative correlations between late-winter ice indices and zonal indices of the subsequent months are clearly seen. Positive correlations are obtained for the summer-fall ice versus the zonal indices of the following winter months. For example, the August-October ice versus November zonal index coefficient is 0.50 . The chance of randomly obtaining three such high values following each other is less than $1 \%$. Furthermore, the meridional index and the temperature index of the polar atmosphere were correlated with the seaice extent but, due to space limitations, are not presented here.

According to the foregoing analysis, the following conclusions are suggested. Sea-ice conditions have two opposing effects on the general circulation of the atmosphere, depending on the season. Heavy ice conditions in winter cause strong zonal circulation, weak meridional circulation, and low polar temperatures in the subsequent months. However, from the late summer to the following winter, the effect acts in the opposite way. Light ice conditions in late summer-fall cause strong zonal circulation, weak meridional circulation, and low polar temperature in the subsequent months. Time lags are 1-4 months. It is interesting that, in spite of their small inter-annual variability, ice conditions in the Atlantic sector have a stronger effect on the atmosphere than ice conditions in the Pacific sector. This is probably because the ocean area in the Atlantic around the ice limit is large, the persistence of the ice conditions is large, and the temperature contrast at the sea surface is large due to warm currents.

Regarding the effect of the atmosphere on the sea ice, significant relationships are obtained in summer. Strong zonal circulation, together with weak meridional circulation and low polar temperatures, causes heavy ice conditions (Nagashima, 1982). Time lags are 1-2 months. Ice in the Pacific sector shows more tendency to be affected by the atmosphere than that in the Atlantic sector. This fact is reflected by the large inter-annual variability of the ice in the Pacific sector. Numerical experiments would be desirable to verify our results.

\section{ACKNOWLEDGEMENTS}

This work is the result of research supported by the Alaska Sea Grant College Program, Department of Commerce, under grant number NA82AA-D-00009, project number $R / 46-02$. We wish to express our thanks to $\mathrm{Dr} F$. Eaton, Dr K. de la Fuente, Dr T. Ohtake, Dr G. Shaw, and Dr G. Weller, who advised us on one aspect or other of this study. Furthermore, our special thanks are due to Dr J. Walsh for providing his data set.

\section{REFERENCES}

Fletcher, J.O. 1965. The heat budget of the Arctic basin and its relation to climate. Santa Monica, CA, Rand Corporation. (R-444-PR.)

Fletcher, J.O. 1969. Ice extent on the Southern Ocean and its relation to world climate. Santa Monica, CA, Rand Corporation. (RM-5793-NSF.)

Johnson, C.M. 1980. Wintertime Arctic Sea ice extremes and the simultaneous atmospheric circulation. Monthly Weather Review, Vol. 108, No. 11, p. 1782-91.

Loon, H. van. 1979. The association between latitudinal temperature gradient and eddy transport. Part I. Transport of sensible heat in winter. Monthly Weather Review, Vol. 107 , p. $525-34$.

Muench, R.D., and Ahlnas, K. 1976. Ice movement and distribution in the Bering Sea from March to June 1974. Journal of Geophysical Research, Vol. 81, No. 24, p. 4467-76.

Nagashima, Y. Unpublished. Interrelations between the Arctic sea ice and the general circulation of the atmosphere. [Master's thesis, University of Alaska, 1982.]

Walsh, J.E., and Johnson, C.M. 1979[a]. An analysis of Arctic sea ice fluctuations, 1953-77. Journal of Physical Oceanography, Vol. 9, No. 3, p. 580-91.

Walsh, J.E., and Johnson, C.M. 1979[b]. Interannual atmospheric variability and associated fluctuations in Arctic sea ice extent. Journal of Geophysical Research, Vol. 84, No. C11, p. 6915-28. 